TI 2006-031/3

Tinbergen Institute Discussion Paper

The Impact of Rail Transport on Real Estate Prices:

An Empirical Analysis of the Dutch Housing Markets

Ghebreegziabiher Debrezion

Eric Pels

Piet Rietveld

Vrije Universiteit Amsterdam, and Tinbergen Institute. 


\section{Tinbergen Institute}

The Tinbergen Institute is the institute for economic research of the Erasmus Universiteit Rotterdam, Universiteit van Amsterdam, and Vrije Universiteit Amsterdam.

Tinbergen Institute Amsterdam

Roetersstraat 31

1018 WB Amsterdam

The Netherlands

Tel.: $\quad+31(0) 205513500$

Fax: $\quad+31(0) 205513555$

Tinbergen Institute Rotterdam

Burg. Oudlaan 50

3062 PA Rotterdam

The Netherlands

Tel.: $\quad+31(0) 104088900$

Fax: $\quad+31(0) 104089031$

Please send questions and/or remarks of nonscientific nature to driessen@tinbergen.nl.

Most TI discussion papers can be downloaded at http://www.tinbergen.nl. 


\title{
The impact of rail transport on real estate prices: an empirical analysis of the Dutch housing market
}

\author{
Ghebreegziabiher Debrezion \\ Eric Pels \\ Piet Rietveld \\ Free University, Department of Spatial Economics \\ De Boelelaan 1105, 1081 HV Amsterdam \\ Tel: +31205986090 \\ Fax: +31205986004 \\ E-mail: gdebrezion@ feweb.vu.nl
}

March 2006

\begin{abstract}
:
A hedonic pricing model is estimated to analyse the impact of railways on house prices in terms of distance to railway station, frequency of railway services and distance to the railway line. Correcting for a wide range of other determinants of house prices we find that dwellings very close to a station are on average about $25 \%$ more expensive than dwellings at a distance of 15 kilometres or more. A doubling of frequency leads to an increase of house values of about $2.5 \%$, ranging from $3.5 \%$ for houses close to the station to $1.3 \%$ for houses far away. Finally we find a negative effect of distance to railways, probably due to noise effects. Two railway station references were used in the analysis: the nearest and most frequently chosen station in the post code area. This distinction indicates that railway station accessibility is a more complex concept than one might think. It involves competition between railway stations.
\end{abstract}

Key words: property value, railway station, accessibility, hedonic pricing method. 


\section{INTRODUCTION}

Hedonic pricing methods explain the value of real estate in terms of the features of the property. This approach treats a certain property as a composite of characteristics to which value can be attached. The sum of the value of the individual characteristics makes up the value of the property as a whole. Studies on real estate prices generally categorise the value bearing features of properties into three types namely: physical, accessibly and environmental (Fujita 1989; Bowes and Ihlanfeldt 2001). Several studies have been conducted focusing on different features of interest. Accessibility as provided by different modes of transportation and railways in particular also received attention. In order to single out the effect of railway stations on property values, it is suggested in the literature that stations should be seen as nodes in a transport network and places in an area (Bertolini and Spit 1998). Based on this framework, recent empirical studies treat the node feature and the place feature of a station separately. The former characteristic accounts for the accessibility effect, which is generally positive. The latter feature accounts for externalities of the station and can have both positive and negative effects. Bowes and Ihlanfeldt (2001) pointed at the retail employment and crime that stations attract in addition to the accessibility feature of a station. By including the three categories of property features mentioned above this paper examines the effect of railway stations on Dutch house prices. There are three types of rail service in the Netherlands: light rail services (trams), heavy rail services (metro lines) and commuter rail services. The services of the first two are limited within the main cities. However, the third type serves the whole country. This paper assesses the effect of accessibility provided by these commuter railway stations on the prices of these houses. As a main accessibility competitor to railways, highway accessibility is represented in our analysis by means of distance to points of highway entry and exits.

The accessibility and nuisance effects of a railway station are functions of distance between the station and the house under consideration. As the distance increases, the impact of both features on the house price declines. The level of accessibility at a railway station is measured by the quality of the railway network: the number of destinations that can be reached from the station, the frequency of services at the station, and other departure station related facilities. Stations with higher network quality (i.e. a larger number of destinations and a higher frequency of trains) have a higher accessibility index, and are expected to have a relatively high positive effect on the 
house prices. Railway stations at the same time impose localised negative environmental effects on house prices due to noise nuisance. An important difference between the two effects is that the accessibility effects are concentrated around nodes (railway stations) whereas the negative noise effects take place everywhere along the railway line.

In this paper we determine the impact of the three railway features namely: railway station proximity and rail service levels and proximity to railway line on prices of residential properties. The data for the analysis in this paper includes the sales and prices of residential properties in the Netherlands. Due to the transportation cost and time savings made possible, households are expected to be willing to pay higher prices to living close to the station compared with other locations. This is because the commuting (time) costs are relatively low when one lives near a station. Furthermore, leisure activities that involve rail transport are more accessible. This paper only covers the sales of residential properties. In a follow up paper we intend to cover the effect of railway station on commercial property values.

\section{LITERATURE REVIEW}

Most land value theories have their root in the work of Von Thünen (Von Thünen 1830), who tried to explain variations in farmland values. According to Von Thünen, accessibility to the market place explains the value difference of farmlands for agricultural lands having similar fertility. In subsequent studies, economists like Alonso and Muth refined this line of reasoning into a bid-rent analysis (Alonso 1964; Mute 1969). The basic idea behind the bid-rent model is that every agent is prepared to pay a certain amount of money, depending on the location of the land. This leads to a rent gradient that declines with distance from the central business district (CBD) for sites that yield equal utility. Thus far in the analyses, the dominant factor explaining the difference between land (property) values was the accessibility as measured by the distance to the Central Business District (CBD) and the associated transportation costs. The physical characteristics of the land (fertility in the case of Thünen) were assumed given.

Thus the basic theory on real estate prices can be put forward as follows: as a location becomes more attractive, due to certain characteristics, demand increases and thus the bidding process 
pushes prices up. In most cases CBDs are the centres of many activities. Therefore, proximity to the $\mathrm{CBD}$ is considered as an attractive quality that increases property prices. However, investments in transport infrastructure reduce this demand friction around the CBD to some degree (Fejarang 1994) by attracting households to settle around the stations. Properties close to the investment area (railway stations) enjoy benefits from transportation time and cost saving as a result of the investment. It may be expected that a price curve will have a negative slope; when we move away from the station, prices decrease.

The introduction of the hedonic pricing methodology by Rosen (1974) led to an easier way of attributing value to the properties' features. Therefore, in subsequent studies we observe the integration of physical, accessibility and environmental characteristics of the property in models trying to explain the differences in property values. Accessibility remains an important feature for urban properties. However, earlier attempts to account for it by using transportation cost have been narrow. Attempts have been made to introduce a broader concept of accessibility by including all features that contribute to the potential of opportunities of a location for economic and social interactions (Hansen 1959; Martellato et al. 1998). Though a comprehensive definition of the concept is available, the lack of data and appropriate measuring techniques usually implies that simple measures are used. Thus, in the literature we see a focus on a limited number of factors only, especially a CBD oriented interaction related to employment and shopping. In most property value studies, the other trip purposes are missing from the model.

The main focus of this paper is the analysis of the impact of railway accessibility on residential house prices. However, as Voith (1993) pointed out, highway accessibility is an important competitor to rail accessibility. 'The presence of other facilities that increase accessibility like highways, sewer services and other facilities influence the impact area in the same fashion.' The benefits of these facilities and services are also capitalised into urban property values (Damm et al. 1980). Thus, to single out the effect of railway accessibility, competing modes of accessibility need to be included along with it.

The motivations for the studies on the impact of railway accessibility are diverse. The larger part of the literature on railways focuses on it as a feasible solution to the rising congestion posed by automobile traffic and urban sprawl. Railway investment is expected to support a more compact 
urban structure and therefore it serves the urban planning purpose (Goldberg 1981). Apart from reasons of showing that railway investments do result in compact urbanisation, most studies in the area were conducted to provide evidence for the implementation of value capture schemes for financing rail investments (Cervero and Susantono 1999). This was based on the assertion that the value of proximity to accessibility points is capitalised on the value of properties around these stations.

In general, the empirical studies conducted in this area are diverse in methodology and focus. Although the functional forms can differ from study to study, the most common methodology encountered in the literature is hedonic pricing. However, no consistent relationship between proximity to railway stations and property values is recorded. Furthermore, the magnitudes of these effects can be minor or major. One of the earliest studies, Dewees (1976) analysed the relationship between travel costs by railway and residential property values. Dewees found that a subway station increases the site rent perpendicular to the facility within a one-third mile to the station. Similar findings confirmed that the distance of a lot from the nearest station has a statistically significant effect on the property value of the land (Damm et al. 1980). Consistent with these conclusions, Grass (1992) later found a direct relationship between the distance of the newly opened metro and residential property values. Some of the extensively studied metro stations in the U.S., though ranging from small to modest impact, show that properties close to the station have a higher value than properties farther away (Giuliano 1986; Bajic 1983; Voith 1991). However, there are studies which have also found insignificant effects (Lee 1973; Gatzlaff and Smith 1993). On the other hand, contrary to the general assumption, Dornbusch (1975) and Landis et al. (1995) traced a negative effect of station proximity. Evidence from other studies indicates little impact in the absence of favourable factors (Gordon and Richardson 1989; Giuliano 1986). For a detailed documentation of the findings, we refer to (Vessali 1996; Smith and Huang 1995; NEORail 2001;NICS 2002). In general, some studies indicate a decline in the historical impact of railway stations on property values. This was attributed to improvements in accessibility, advances in telecommunications, computer networks, and other areas of technology that were said to make companies "footloose" in their location choices (Gatzlaff and Smith 1993). 
The impact of railway stations on property values varies due to several factors. First, railway stations differ from each other in terms of the level of service provided explained terms of frequency of service, network connectivity, service coverage etc. The meta analysis in Debrezion et al. (2006) shows that different types of railway stations have different levels of impact on property value. Commuter railways have a relatively high impact on property value (Debrezion et al. 2006; Cervero and Duncan 2001; NEORail 2001; Cervero 1984). Railway stations also differ in the level and quality of facilities. Stations with higher level and quality of facilities are expected to have greater impact on the surrounding properties. The presence and number of parking lots is one of the many station facilities that got attention in the literature. Bowes and Ihlanfeldt (2001) found that stations with parking facilities have a higher positive impact on property values. In addition, the impact a railway station produces depends on its proximity to the CBD. Stations which lie close to the CBD produce a greater positive impact on the property value (Bowes and Ihlanfeldt 2001). In another study, Gatzlaff and Smith (1993) claim that the variation in the findings of the empirical work is attributed to local factors in each city.

Second, railway stations affect residential and commercial properties differently. Most studies have treated the effect of railway stations on the different property types separately. The range of the impact area of railway stations is larger for residential properties, whereas the impact of a railway station on commercial properties is limited to immediately adjacent areas. Generally, it has been shown that the impact of railway stations on commercial properties is greater than the impact on residential properties within short distance of the stations (Cervero and Duncan 2001; Weinstein and Clower 1999). This finding is in line with the assertion that railway stations - as focal, gathering points - attract commercial activities, which increase commercial property values. However, contrary to this assertion, Landis et al. (1995) determined a negative effect on commercial property values.

Third, the impact of railway stations on property value is subject to demographic segmentation of neighbourhoods. Income and social (racial) divisions are common. Proximity to a railway station is of higher value to low-income residential neighbourhoods than to high-income residential neighbourhoods (Nelson 1998; Bowes and Ihlanfeldt 2001). The reason is that lowincome residents tend to rely on public transit and thus attach higher value to living close to the station. Because of the fact that this group of people mostly depend on slow modes (walking and 
bicycle) to access the stations, railway station adjacent locations are expected to constitute poor segments. On the other hand, the high population movement in the immediate location gives rise to the development of retail activities which eventually capitalize on commercial properties, but it may at the same time attract criminality (Bowes and Ihlanfeldt 2001). Bowes and Ihlanfeldt outlined that a significant relation was observed between stations and crime rates. However, no proximity variable shows a significant effect on retail employment. In this model, the immediate neighbourhood is affected by the negative impact of the station. Thus the most immediate properties (within a quarter of a mile of the station) were found to have an $18.7 \%$ lower value. Properties that are situated between one and three miles from the station, however, are more valuable than those further away.

\section{DATA AND DESCRIPTIVES}

\section{(A) HOUSE CHARACTERISTICS}

The data used in the analysis of this paper covers sales transactions of the Dutch residential housing market for a period of seventeen years from 1985 to 2001. These transactions are recorded by the Dutch Brokers Association (NVM). The data incorporate information related to price of the dwellings, characteristics of the dwellings and some environmental features. To further enrich the data set, each of the houses sold is geo-coded separately to enable us to compute the distances to the railway stations and highway entry/exit points. Some houses are geo-coded at the precise house address level and the rest are geo-coded at the six digit (e.g. 1234XX) post code level, which is an area comprising up to about 50 houses. Apart from the house characteristics, a number of accessibility and neighbourhood features are used. The land use data were acquired from the central office of statistics for the Netherlands (the CBS). These data are available at the four-digit postal code level. Moreover, population related data are available at this level of aggregation. Income levels of the population in the post code area, the density and population composition in particular the share of foreigners in the area, are used in our analysis. 
The accessibility data relate to two transport modes: railway and highway. The locations of all railway stations and highway entry/exit points are identified. The distance from the houses to these points was determined by GIS methods. The distance to the nearest highway entry/ exit points is expected to account for the car based accessibility. This paper uses two references for a railway station: the nearest railway station and the most frequently chosen railway station. The nearest station is easily determined using GIS methods. The identification of the most frequently chosen station was based on the survey study of the Dutch National Railway Company (NS). It is given at the 4-digit post code area level.

\section{Tables:}

Table 1: Descriptive statistics of house characteristics

Minimum Maximum Mean Std.

Deviation

\section{Dependent variable}

Transaction price in Euros

\section{Independent variables}

1. House features

Surface area in sq. meters

Building age in years

Total number of rooms

Number of bathrooms

Dummy variables

Monument

Gas heater

Open fireplace

Garage

Garden

2. accessibility features

Distance to nearest railway station (m)

Distance to most frequently chosen railway station (m)

Frequency (trains/day at the most frequently chosen station)

Frequency (at the nearest station)

Distance to highway entry/exit (m)

3. environmental

Household income in Euros (4 digit postcode level)

Population composition (percentage of foreigners)
9076

$5,558,800123,187$

95,678

$\begin{array}{cccc}11 & 99,998 & 443 & 1890 \\ 0 & 996 & 38 & 40 \\ 1 & 39 & 4.47 & 1.34 \\ 0 & 4 & 0.87 & 0.58\end{array}$

0.009

0.136

0.186

0.335

0.783

$\begin{array}{cccc}3 & 25,498 & 3,486 & 3441 \\ 10 & 35,643 & 4,245 & 5064 \\ 18 & 788 & 268 & 217 \\ & & & \\ 18 & 788 & 169 & 151 \\ 0 & 39,541 & 3,978 & 4711\end{array}$

3136

26200

11480

1805

$\begin{array}{llll}0.010 & .890 \quad .642 & 0.918\end{array}$


In Table 1 above some descriptive statistics on the three categories of factors affecting property values are given. For the physical features of the houses we use a large number of relevant items. Examples are surface area of the house (that includes the built up and non-built up part of the property), age of the house, the number of rooms and number of bathrooms; all these variables are continuous. The rest of the physical characteristics, such as monumental status of the dwelling, the availability of gas heater, the presence of open fire place, the presence of garden and garage are indicated by dummy variables. The mean values for some of these features are given in Table 1. The descriptive statistics are based on 663,024 houses sold in the time period considered. The features in the accessibility category include distance to the railway station, the frequency of trains and the distance to the nearest highway entry/exit point (both with respect to the most frequently chosen station for residents in the post code area and the nearest station to the house). The analysis also includes the perpendicular distance to railway lines in an effort to capture the noise effect of railways.

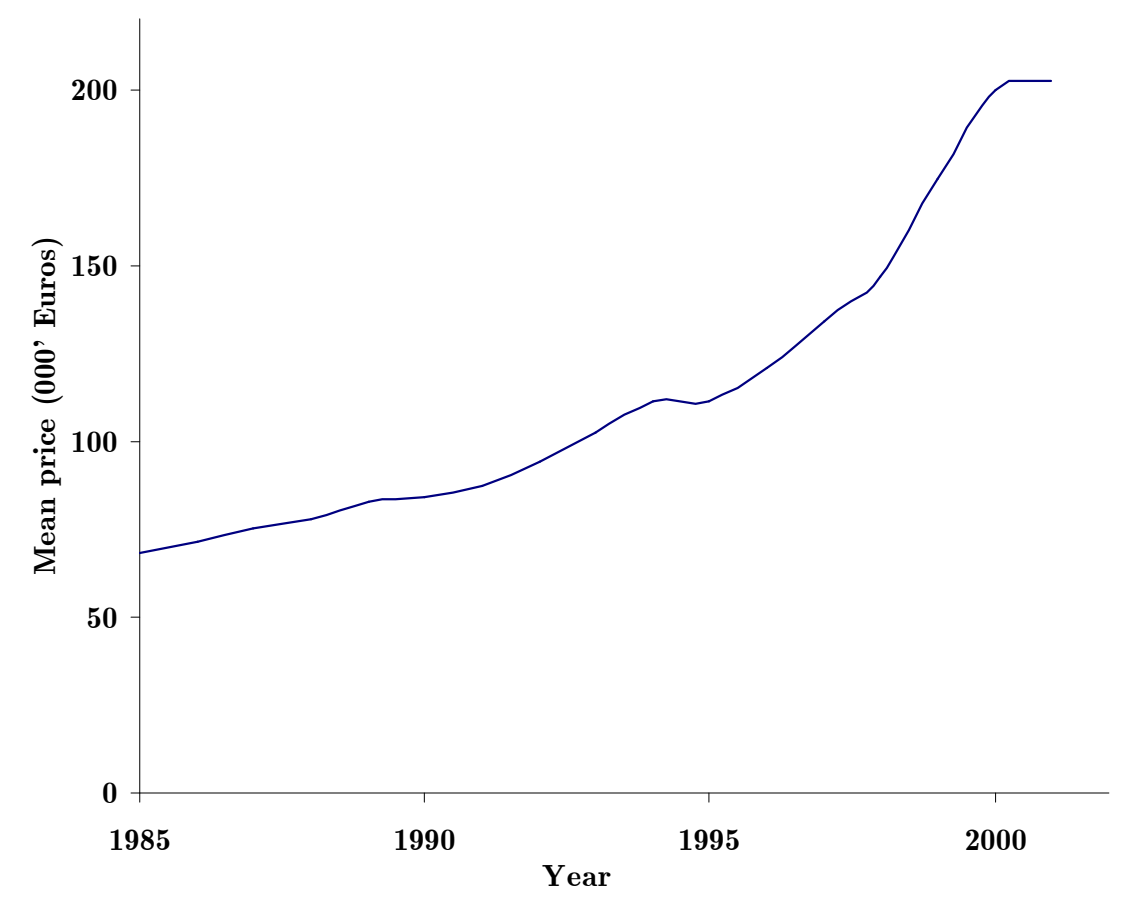

Figure 1: Mean price of houses by year

The distance to the most frequently chosen station is on average about 1 kilometre longer than the average distance to the nearest railway station. The average frequency of trains at the most frequently chosen station is more than 100 trains per day over the average frequency of trains at 
the nearest railway station. This gives and indication of the trade-off travellers make between proximity of stations and the level of service they offer. Figure 1 shows the average transaction price in each year. This increase can be attributed to combined effect of inflation and real value increase.

\section{(B) RAILWAY STATION CHARACTERISTICS}

The data of particular interest in this study concerns the railway accessibility and associated noise or congestion. Railway accessibility can be explained by two features: the proximity feature and service level features. The first feature is more or less captured by the distance measure whereas various features can contribute to the service level. Examples include the number of trains leaving the station per time unit, and network connectivity as measured by the number of destinations served by the station. In addition, it may also include facilities that supplement railway transport. For example the availability of parking space, the park and ride status of the station and the availability of bicycle safes can be mentioned. The overall Dutch railway network is composed of about 360 stations. Our data allows us to use the most frequently chosen departure station for households aggregated at the 4-digit post code level.

Table 2: Descriptive statistics for the railway station characteristics

\begin{tabular}{|c|c|c|c|c|c|}
\hline & No. stations & Minimum & Maximum & Mean & Std. Deviation \\
\hline \multicolumn{6}{|c|}{ 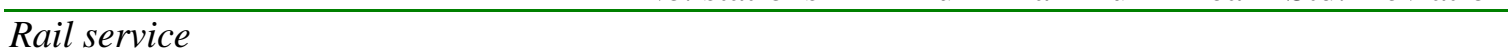 } \\
\hline Frequency of trains per day & & 18 & 788 & 113 & 103 \\
\hline Destinations reached without a transfer & & 1 & 114 & 16 & 14 \\
\hline Destination reached with one transfer & & 8 & 246 & 87 & 53 \\
\hline \multicolumn{6}{|l|}{ Travel demand } \\
\hline Total Passenger turnout per day & & 46 & 145,700 & 5,600 & 13,770 \\
\hline \multicolumn{6}{|l|}{ Station type } \\
\hline Inter-city stations & 64 & & & 0.18 & \\
\hline \multicolumn{6}{|l|}{ Station Facilities (dummy variables) } \\
\hline Train taxi & 109 & & & 0.30 & \\
\hline Bicycle stand & 96 & & & 0.27 & \\
\hline Bicycle safe & 264 & & & 0.74 & \\
\hline Bicycle rent & 114 & & & 0.31 & \\
\hline Park and Ride & 49 & & & 0.14 & \\
\hline Parking & 326 & & & 0.91 & \\
\hline Taxi & 163 & & & 0.45 & \\
\hline Car rent & 1 & & & 0.00 & \\
\hline Luggage deposit & 64 & & & 0.18 & \\
\hline International connection & 22 & & & 0.06 & \\
\hline
\end{tabular}




\section{METHODOLOGY}

The hedonic pricing methodology is found to be effective in singling out the effect of one characteristic from a number of characteristics composing a property (Rosen 1974). This paper uses this approach to determine the effect of the three categories of house features in general and railway accessibility in particular. A semi logarithmic specification is adapted. Thus, the dependent variable in our analysis is the natural logarithm of the transaction price of residential houses. A wide range of independent variables that are expected to explain the house prices are included. These include the physical characteristics of the houses, environmental amenities and the accessibility variables that correspond to the houses under study. Due to the fact that the data set covers a relatively long period, and house prices have increased continuously during the last decade temporal effects are also expected to play a role in explaining the variation in the sales price of houses. Thus, we include sales year dummies to capture the temporal effects. These account for the inflation, real value changes and other temporal effects across the time period. To account for the spatial effect regional dummies are included at the municipality level. The main focus of the analysis here is the effect of railway station proximity and service quality of the stations. We also include the effect of proximity to highway entry/exit points to account for competition by the car.

\section{MODEL SPECIFICATION}

Even though the data include a longer period, we could not organise our data in a panel structure because there were not many repeated sales over the time. Therefore, our data is organised in a cross-sectional pattern. The semi logarithmic hedonic specification is widely used in the property value literature. Its use is motivated by the fact it gives robust estimates and it enables convenient coefficient interpretation. The general structure of the model we adopt here is:

$$
\operatorname{Ln}\left(P_{i}\right)=B_{0}+B_{1}^{\prime} X_{i 1}+B_{2}^{\prime} X_{i 2}+\ldots+B_{n}^{\prime} X_{i n}+\varepsilon_{i}
$$

$P_{i}$ is the price house $i, X_{i 1} \ldots X_{i n}$ are vectors of explanatory variables for the price of house $i$. The dependent variable is given in the natural logarithmic form; thus the values of the

coefficients represent percentage change. The specifications used in the estimations are given by equations 2 and 3. Distances from the houses to railway station and line and highway entry /exit 
points are distinguished according to several distance categories. The first model includes the distance and frequency effect (station quality) separately. The second model includes the interaction between distance and frequency. In both specifications proximity to railway station and railway line are treated in piecewise fashion. Frequency of trains at the reference station is given in continuous form. The models have the following form:

$$
\begin{aligned}
& \ln \left(\text { tranPrice }_{i}\right)=\alpha+\beta^{\prime}{ }_{H C} \times \text { HouseCh }_{i}+\beta^{\prime}{ }_{d c} \times \text { Distcategrail }_{i}+\beta_{\text {freq }} \times \ln \left(\text { Freq }_{i}\right) \\
& +\beta^{\prime}{ }_{h w} \times \text { Distcateghway }_{i}+\beta^{\prime}{ }_{\text {railline }} \times \text { Drailline }_{i}+\beta^{\prime}{ }_{\text {Neighb }} \times \text { Neighb }_{i} \\
& +\beta_{\text {Re gion }}^{\prime} \times \text { Dregional }_{i}+\beta_{\text {time }^{\prime}}^{\prime} \times \text { Ditime }_{i}+\varepsilon_{i} \\
& \ln \left(\operatorname{tranPrice}_{i}\right)=\alpha+\beta^{\prime}{ }_{H C} \times \text { HouseCh }_{i}+\beta^{\prime}{ }_{D C \otimes F r e q} \times \text { Distcategrail }_{i} \otimes \ln \left(\text { Freq }_{i}\right) \\
& +\beta^{\prime}{ }_{h w} \times \text { Distcateghway }_{i}+\beta_{\text {railline }^{\prime}} \times \text { Drailline }_{i}+\beta_{{ }_{\text {Neighb }}} \times \text { Neighb }_{i} \\
& +\beta_{\text {Re gion }}^{\prime} \times \text { Dregional }_{i}+\beta_{\text {time }}^{\prime} \times \text { Dtime }_{i}+\varepsilon_{i}
\end{aligned}
$$

Where tranPrice ${ }_{i}$ represents the transaction price of house $i$; HouseChr $r_{i}$ is a vector of house characteristics for house $i$, which includes variables for type of house, surface area, total number of rooms, number of bathrooms, presence of garage and garden for the house, presence of gas heater and fire place, monument, age of the building; Distcategrail ${ }_{i}$ is a vector of dummy variables representing the distance category at which house $i$ is located from a station. To see the smoothness of the effect we use a 500 meters range categories except in the two inner circle categories of the station, which are 250 meters each. Thus we have 31 categories of distances up to 15,000 meter. Areas beyond this limit are taken as a reference group in the estimation. FreqT is the frequency of trains at the station to which the distance is computed and is given in trains per day. In our analysis we make two station considerations: the nearest vs the most frequently chosen station in the post-code area. $\otimes$ is the Kronecker product to indicate the cross production of distance classes and frequency of trains at the reference station. Distcateghway ${ }_{i}$ is a vector of dummies representing the distance category at which a highway entry/exit point is located from the house. In the same fashion as the railway distance categories, we also have 31 distance categories for these variables. Drailline ${ }_{i}$ is a vector of two dummy variables representing at which distance category the house is locating from the railway line. This is expected to account for the noise effect of trains. The railway noise is expected to have localized effect and thus we 
compare the effect of noise on two nearby distance against rest. Neighb $b_{i}$ is a vector of neighborhood characteristics including income, ratio of foreigners and rate of land use types. It is given at the four-digit post code level. Dregional $_{i}$ is a vector of dummy variables representing to which municipality the house belongs. Dtime $e_{i}$ is a vector of time dummy variables representing the year when the transaction took place. $\varepsilon_{i}$ is the error term.

The accessibility related variables included are the distances to the railway stations, the frequency of trains at the stations and highway entry/ exit points. The structural features considered are the type of the houses, surface area of the houses, total number of rooms, number of bathrooms, presence of garage, garden, gas heater and fire place, monumental status of the houses, and age of the houses. Variables included under the environmental features are average household income, ratio of foreigners, and rate land use types at the post code level and regional municipality dummy variables. The distance to the railway line is another variable that can be considered under the environmental variables. Year dummies are also used to account for the temporal effect. All in all the total number of explanatory variables in the hedonic pricing models is 344 . Of these 34 relate to house characteristics, 28 to neighbourhood features, 16 to time series dummies and 203 to municipality dummies. The remaining 63 variables represent railway and highway accessibility. In the presentation of estimations below we focus on the impact of the accessibility variables. The municipality dummies can be considered to represent the many municipality specific factors that may affect house values. Thus, the effects we find for the railway station proximity have been corrected for municipality specific impacts.

Generally, the price of houses is expected to rise as one comes close to the railway station and/or highway entry/exit points. At the same time, the influence of a station to the house prices is expected to increase with the increase in the service level provided by the station as given by frequency of trains and the number of destinations directly served by the station. However, the latter two variables are highly correlated, thus we prefer to include one of the two in our estimation. We find the frequency variable more telling since it addresses scheduling and waiting time aspects, an important dimension of generalized costs. In addition, frequency is related to reliability since delays are less disturbing in the case of high frequency. 


\section{ESTIMATION RESULTS AND DISCUSSIONS}

Table 3 gives four estimation results based on equations 2 and 3. To save space we only report the coefficients of the factors that relate to railway aspects. The complete estimation results are available upon request from the authors. The first two estimations correspond to the simple linear effect of piecewise distances and frequency of trains effect treated separately as given by Equation 2. The last two estimations are based on the model given by Equation 3. The cross distance-frequency estimation gives the effect of frequency of trains on house prices for each of the distance classes. The semi-log nature of the model makes the interpretation of the coefficients easier. Each coefficient for the distance categories in the first two estimations shows the percentage effect on house prices of distance to the station compared to houses located beyond 15 kilometres. Thus, we observe a difference as big as 32\% in house prices for houses within $500 \mathrm{~m}$ of the nearest station and houses beyond 15 kilometres from the stations. This difference gets smaller in the case of the most frequently chosen station effect (about 27\%), where we encounter the peak house price to be between 250 and 500 metres. The trend of the effect sizes for this specification is given in Figure 2. This figure shows irregularity in the distance category of 7.5 to 8 kilometers. This is due to the small number of observations in this category. Such irregularities are inevitable when small distance classes are used. The difference between the distance effect of the nearest and most frequently chosen station is remarkable. The advantage of being close to the station is not so large in the case of the most frequently chosen station compared with the nearest station. The reason is that the most frequently chosen station apparently has extra qualities that make it more attractive than the nearest station. Hence, one may expect that distance to the station matters less in the price effect on real estate. The mirror image is that the quality of the station, as reflected among others by the frequency, has a larger effect. This explains why the frequency elasticity in Table 3 is so high for the most frequently chosen station compared with the nearest station ( 0.09 versus 0.03$)$. A doubling of frequency of trains at the most frequently chosen station has $9 \%$ house price increase in the post code area compared to $3 \%$ for the case of the nearest railway station (see the first 2 columns of Table 3 ). Finally, we find clear negative effects of railway noise on house values: houses located in the zone within 250 meters from a railway line are about 5\% less expensive than houses located 500 meters or more. For the zone between 250-500 meters intermediate values are found. 
However, the measure of frequency of trains' effect discussed above is crude since it is not distance dependent. The point is that for dwellings close to a station a frequency increase is probably of more importance than for dwellings far away. The last two columns of Table 3 provide the estimation of the cross distance-frequency effect. Doubling the frequency of trains in the nearest station results in as much as 3.5\% price increase for houses located up to 2 kilometres compared to the effect on dwellings located beyond 15 kilometres. Doubling the frequency of the most frequently chosen station on the other hand results in about 3.0\% price increase for the same distance section. The pattern in the elasticities of frequency for the different distance categories is depicted graphically in Figure 3. These estimations demonstrate that the value of property may depend on the proximity to more than one railway station. We will not investigate this issue in more detail here, but this is an indication that railway station accessibility is a more complex concept than one might think: it involves competition between railway stations.

Furthermore, the percentage effect of different levels of frequency is given in Table 4 below. The table shows -not surprisingly- that the effect of railway proximity is largest in the case of a station with a high level of service. Note that such a differentiated effect is not present in the specification given by Equation 2. However, the frequency impact is smaller than one might expect. The price curves are clearly steeper around stations with higher frequencies. Further, we find that even for stations with a small number of trains a substantial effect of railway presence is found. Note that this estimation is based on a specification where corrections were carried out for a large number of other variables. In particular, a dummy has been added for each municipality so that it has been assured that the results found do not capture the effects of other variables such as population density or other municipality specific factors. 
Table 3: Estimation of Railway station effects on house values: piecewise distance effect (N.B. Only railway related parameters are presented)

\begin{tabular}{|c|c|c|c|c|c|c|c|c|}
\hline \multirow[t]{3}{*}{ Variable } & \multirow{2}{*}{\multicolumn{2}{|c|}{ Nearest Station }} & \multirow{2}{*}{\multicolumn{2}{|c|}{$\begin{array}{l}\text { Most frequently } \\
\text { chosen station }\end{array}$}} & \multicolumn{4}{|c|}{ Cross distance-frequency of trains effect } \\
\hline & & & & & \multicolumn{2}{|c|}{ Nearest Station } & \multicolumn{2}{|c|}{$\begin{array}{l}\text { Most frequently } \\
\text { chosen Station }\end{array}$} \\
\hline & Coefficient & S.E. & Coefficient & S.E. & Coefficient & S.E. & Coefficient & S.E. \\
\hline (Constant) & $8.966^{* * *}$ & 0.009 & $8.775^{* * * *}$ & 0.009 & $9.189^{* * *}$ & 0.008 & $9.232^{* * *}$ & 0.008 \\
\hline raildist 250 & $0.323^{* * *}$ & 0.006 & $0.271^{* * *}$ & 0.004 & $0.050^{* * * *}$ & $\overline{0.001}$ & $0.043^{* * *}$ & 0.001 \\
\hline raildist250_500 & $0.321^{* * * *}$ & 0.005 & $0.274^{* * *}$ & 0.003 & $0.050^{* * *}$ & 0.001 & $0.044^{* * *}$ & 0.001 \\
\hline raildist500_1000 & $0.315^{* * *}$ & 0.005 & $0.260^{* * *}$ & 0.003 & $0.049^{* * *}$ & 0.001 & $0.043^{* * *}$ & 0.001 \\
\hline raildist1000_1500 & $0.308^{* * *}$ & 0.005 & $0.246^{* * *}$ & 0.003 & $0.048^{* * *}$ & 0.001 & $0.042^{* * *}$ & 0.001 \\
\hline raildist1500_2000 & $0.316^{* * * *}$ & 0.005 & $0.245^{* * *}$ & 0.003 & $0.049^{* * * *}$ & 0.001 & $0.043^{* * *}$ & 0.001 \\
\hline raildist2000_2500 & $0.296^{* * *}$ & 0.005 & $0.232^{* * *}$ & 0.003 & $0.045^{* * *}$ & 0.001 & $0.041^{* * * *}$ & 0.001 \\
\hline raildist2500_3000 & $0.287^{* * *}$ & 0.005 & $0.203^{* * *}$ & 0.003 & $0.042^{* * *}$ & 0.001 & $0.036^{* * *}$ & 0.001 \\
\hline raildist3000_3500 & $0.277^{* * *}$ & 0.005 & $0.203^{* * *}$ & 0.003 & $0.041^{* * *}$ & 0.001 & $0.038^{* * *}$ & 0.001 \\
\hline raildist3500_4000 & $0.299^{* * *}$ & 0.005 & $0.201^{* * *}$ & 0.003 & $0.046^{* * *}$ & 0.001 & $0.038^{* * *}$ & 0.001 \\
\hline raildist4000_4500 & $0.284^{* * *}$ & 0.005 & $0.181^{* * *}$ & 0.003 & $0.042^{* * *}$ & 0.001 & $0.035^{* * *}$ & 0.001 \\
\hline raildist4500_5000 & $0.252^{* * *}$ & 0.005 & $0.160^{* * *}$ & 0.003 & $0.037^{* * *}$ & 0.001 & $0.033^{* * *}$ & 0.001 \\
\hline raildist5000_5500 & $0.238^{* * *}$ & 0.005 & $0.153^{* * *}$ & 0.003 & $0.033^{* * *}$ & 0.001 & $0.033^{* * *}$ & 0.001 \\
\hline raildist5500_6000 & $0.234^{* * *}$ & 0.005 & $0.133^{* * *}$ & 0.004 & $0.033^{* * *}$ & 0.001 & $0.030^{* * *}$ & 0.001 \\
\hline raildist6000_6500 & $0.226^{* * *}$ & 0.006 & $0.106^{* * *}$ & 0.004 & $0.031^{* * * *}$ & 0.001 & $0.027^{* * *}$ & 0.001 \\
\hline raildist6500_7000 & $0.229^{* * *}$ & 0.006 & $0.105^{* * *}$ & 0.004 & $0.032^{* * *}$ & 0.001 & $0.028^{* * *}$ & 0.001 \\
\hline raildist7000_7500 & $0.204^{* * *}$ & 0.006 & $0.093^{* * * *}$ & 0.004 & $0.027^{* * * *}$ & 0.001 & $0.026^{* * *}$ & 0.001 \\
\hline raildist7500_8000 & $0.235^{* * *}$ & 0.006 & $0.006^{* * *}$ & 0.004 & $0.034^{* * * *}$ & 0.001 & $0.009^{* * *}$ & 0.001 \\
\hline raildist8000_8500 & $0.215^{* * * *}$ & 0.006 & $0.065^{* * *}$ & 0.004 & $0.029^{* * *}$ & 0.001 & $0.021^{* * * *}$ & 0.001 \\
\hline raildist8500_9000 & $0.266^{* * *}$ & 0.006 & $0.098^{* * *}$ & 0.004 & $0.040^{* * * *}$ & 0.001 & $0.028^{* * *}$ & 0.001 \\
\hline raildist9000_9500 & $0.213^{* * *}$ & 0.007 & $0.106^{* * *}$ & 0.004 & $0.029^{* * * *}$ & 0.001 & $0.030^{* * *}$ & 0.001 \\
\hline raildist9500_10000 & $0.177^{* * *}$ & 0.007 & $0.100^{* * *}$ & 0.004 & $0.023^{* * *}$ & 0.001 & $0.028^{* * *}$ & 0.001 \\
\hline raildist10000_10500 & $0.158^{* * * *}$ & 0.007 & $0.047^{* * *}$ & 0.005 & $0.019^{* * * *}$ & 0.001 & $0.018^{* * * *}$ & 0.001 \\
\hline raildist10500_11000 & $0.069^{* * *}$ & 0.007 & $0.040^{* * *}$ & 0.005 & 0.002 & 0.001 & $0.017^{* * * *}$ & 0.001 \\
\hline raildist11000_11500 & $0.037^{* * *}$ & 0.008 & $0.038^{* * *}$ & 0.005 & $-0.005^{\text {*** }}$ & 0.002 & $0.016^{* * *}$ & 0.001 \\
\hline raildist11500_12000 & $0.036^{* * * *}$ & 0.008 & $0.053^{* * *}$ & 0.005 & $-0.006^{* * *}$ & 0.002 & $0.022^{* * *}$ & 0.001 \\
\hline raildist12000_12500 & $0.036^{* * *}$ & 0.009 & $0.070^{* * *}$ & 0.005 & $-0.005^{* * *}$ & 0.002 & $0.026^{* * *}$ & 0.001 \\
\hline raildist12500_13000 & $0.022^{* * *}$ & 0.009 & $0.070^{* * *}$ & 0.005 & $-0.011^{* * *}$ & 0.002 & $0.024^{* * *}$ & 0.001 \\
\hline raildist13000_13500 & 0.007 & 0.009 & $0.047^{* * *}$ & 0.005 & $-0.013^{* * *}$ & 0.002 & $0.020^{* * * *}$ & 0.001 \\
\hline raildist13500_14000 & $0.028^{* * * *}$ & 0.008 & $0.034^{* * *}$ & 0.005 & $-0.007^{* * *}$ & 0.002 & $0.016^{* * * *}$ & 0.001 \\
\hline raildist14000_14500 & $0.031^{* * * *}$ & 0.008 & $0.062^{* * *}$ & 0.005 & -0.003 & 0.002 & $0.021^{* * * *}$ & 0.001 \\
\hline raildist14500_15000 & $0.029^{* * * *}$ & 0.009 & $0.035^{* * *}$ & 0.005 & -0.002 & 0.002 & $0.015^{* * * *}$ & 0.001 \\
\hline $\log$ (frequency) & $0.033^{* * *}$ & 0.001 & $0.096^{* * *}$ & 0.001 & & & & \\
\hline railline250 & $-0.051^{* * *}$ & 0.001 & $-0.055^{* * *}$ & 0.001 & -0.050 & 0.001 & $-0.047^{* * *}$ & 0.001 \\
\hline railline250_500 & $-0.038^{* * *}$ & 0.001 & $-0.042^{* * * *}$ & 0.001 & -0.037 & 0.001 & $-0.036^{* * * *}$ & 0.001 \\
\hline R square & \multicolumn{2}{|c|}{0.829} & \multicolumn{2}{|c|}{0.831} & \multicolumn{2}{|c|}{0.829} & \multicolumn{2}{|c|}{0.830} \\
\hline $\mathrm{N}$ & \multicolumn{2}{|c|}{542,884} & \multicolumn{2}{|c|}{543,873} & \multicolumn{2}{|c|}{542,884} & \multicolumn{2}{|c|}{543,873} \\
\hline
\end{tabular}

Linear regression model coefficients with standard errors of the estimates in parentheses

**** stands for a significance level of less than $1 \%$

*** stands for a significance level of less than $5 \%$

* stands for a significance level of less than $10 \%$ 

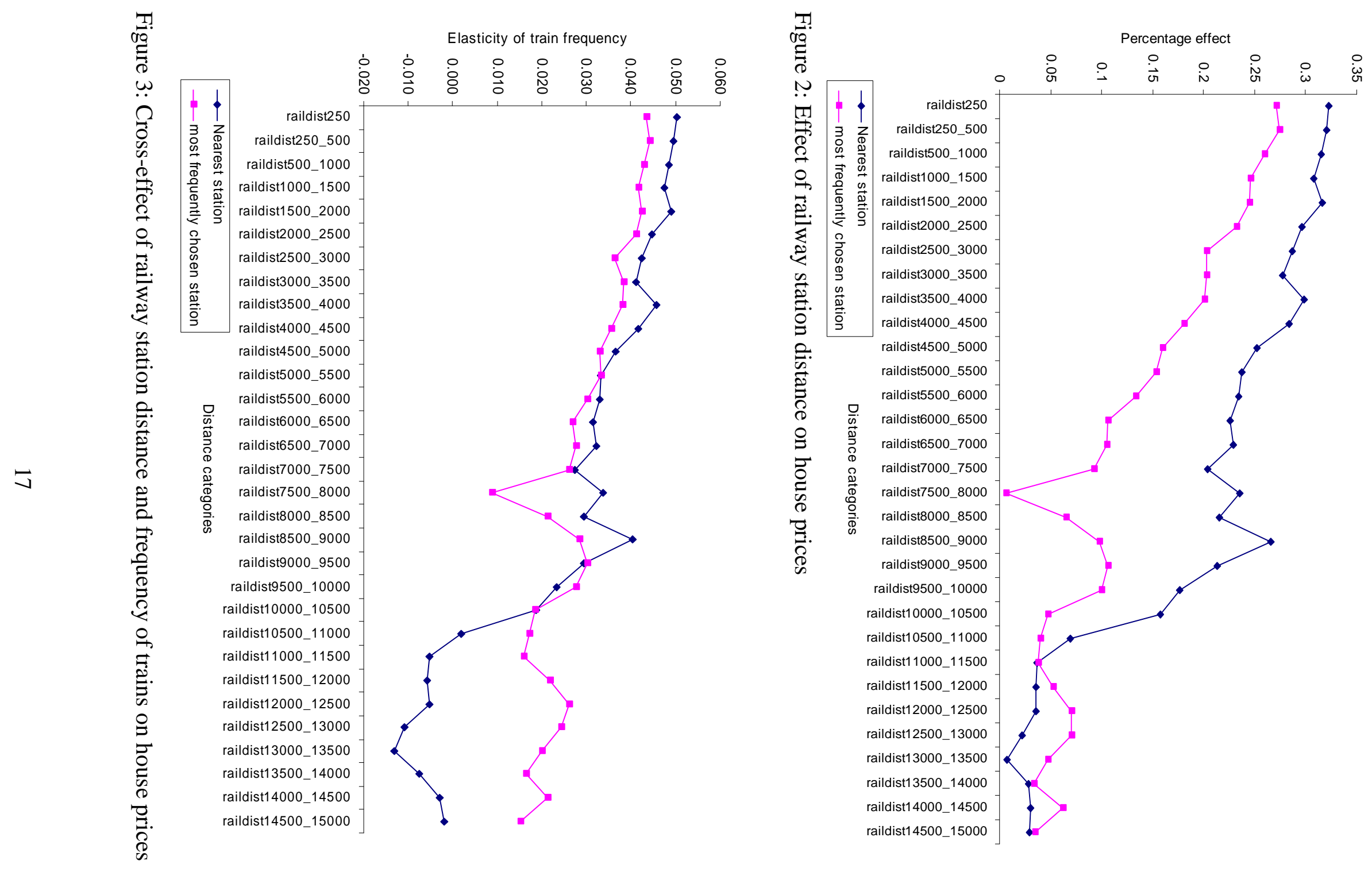
Table 4: The relative price difference of dwellings at sample distances compared with dwellings located beyond 15 kilometres. (Based on cross distance -frequency specification)

\begin{tabular}{|c|c|c|c|c|c|c|}
\hline \multirow[b]{2}{*}{$\begin{array}{l}\text { Distance } \\
\text { Frequency } \\
\text { (trains/day) }\end{array}$} & \multicolumn{2}{|l|}{$0-250 \mathrm{~m}$} & \multicolumn{2}{|c|}{$5000-5500 \mathrm{~m}$} & \multicolumn{2}{|c|}{$10000-10500 \mathrm{~m}$} \\
\hline & $\begin{array}{l}\text { Nearest } \\
\text { station }\end{array}$ & $\begin{array}{l}\text { Mostly } \\
\text { chosen } \\
\text { station }\end{array}$ & $\begin{array}{l}\text { Nearest } \\
\text { station }\end{array}$ & $\begin{array}{l}\text { Mostly } \\
\text { chosen } \\
\text { station }\end{array}$ & $\begin{array}{l}\text { Nearest } \\
\text { station }\end{array}$ & $\begin{array}{l}\text { Mostly } \\
\text { chosen } \\
\text { station }\end{array}$ \\
\hline 50 & $19.6 \%$ & $16.8 \%$ & $12.9 \%$ & $12.9 \%$ & $7.4 \%$ & $7.0 \%$ \\
\hline 100 & $23.0 \%$ & $19.8 \%$ & $15.2 \%$ & $15.2 \%$ & $8.7 \%$ & $8.3 \%$ \\
\hline 200 & $26.5 \%$ & $22.8 \%$ & $17.5 \%$ & $17.5 \%$ & $10.1 \%$ & $9.5 \%$ \\
\hline 400 & $30.0 \%$ & $25.8 \%$ & $19.8 \%$ & $19.8 \%$ & $11.4 \%$ & $10.8 \%$ \\
\hline 800 & $33.4 \%$ & $28.7 \%$ & $22.1 \%$ & $22.1 \%$ & $12.7 \%$ & $12.0 \%$ \\
\hline
\end{tabular}

When one wants to achieve an increase in real estate values along a railway line, there are several strategies. One strategy would be to increase the frequency of service on existing stations, and Table 4 shows the rather modest effects. Another strategy would be to create an extra station. If two stations are located at distances of say 10 kilometres and a new station is built in between the two, the distance to the nearest station decreases up to a maximum of $5 \mathrm{~km}$. As indicated by Table 4, the latter strategy would lead to an increase in house value of at most $6.7 \%(19.6 \%-12.9 \%)$ of the dwellings located in the immediate vicinity of the station. With the present model it is not possible to investigate the consequences of adverse effects on travel times due to the extra stop. Note that, when we compare the effects of creating an extra station or a frequency increase, the first mainly affects property values in one location, whereas the latter would be beneficial for all stations where the train would stop.

\section{SUMMARY AND CONCLUSION}

This paper analyses the effect of railway station accessibility on the house prices. A cross sectional hedonic price model is estimated based on Dutch residential house transaction in the years from 1985 to 2001. The model accounts for physical, environmental, temporal and accessibility features of the residential houses. For each of these features a wide range of 
variables is included. The main focus of this paper is, however, to analyse the effect of accessibility provided by railway transport on property values. Most studies in this area only consider the proximity of properties to railway stations. However, this approach is limited because accessibility of railway stations is more than proximity to railway stations. In other words, railway stations are not chosen as departure points for reasons of proximity alone. Thus, we need a better approach to address railway accessibility in the analysis. Railway accessibility is a function of the distance and the service levels at the relevant departure railway stations. The choice for a departure railway station is also affected by the levels of rail service, network connectivity, service coverage and facilities. Thus, it is possible for the residential property value to react to an important railway station located farther away than a less important one located nearby. In this respect most previous studies had shortcomings in that they neglect the choice process for a departure station in their property value effect analysis by sticking to the nearest railway station. This paper adds to the literature in this area in two respects. First, we make a distinction between the nearest railway station to the property and the most frequently chosen station in the post code area to which the property under consideration belongs. Second, a broader approach for addressing accessibility is applied by taking into account the frequency of services. The effects of proximity and service levels on property values are analysed. In addition we pay attention to the distance to railway lines to reflect potential noise and other disturbance effects.

Correcting for a wide range of other determinants of house prices we find that dwellings very close to a station are on average about $25 \%$ more expensive than dwellings at a distance of 15 kilometres or more. This percentage ranges between 19\% for low frequency stations and 33\% for high frequency stations (see Table 4). A doubling of frequency leads to an increase of house values of about $2.5 \%$, ranging from 3.5 for houses close to the station to $1.3 \%$ for houses far away. Finally we find a negative effect of distance to railways, probably due to noise effects: within the zone up to 250 meters around a railway line prices are about $5 \%$ lower compared with locations further away than 500 meters. As a result of the two distance effects, the price gradient starts to increase as one moves away from a station, followed by a gradual decrease after a distance of about 250 meters. 
Our estimations reveal that the distinction between nearest railway station and most frequently chosen railway station is important. In many cases the traveller does not choose the closest station. This is an indication that railway station accessibility is a more complex concept than one might think, as it involves competition between railway stations, a subject we intend to address in a forthcoming paper.

\section{ACKNOWLEDGEMENT}

We would like to take the opportunity to thank different parties that contributed to our work by providing data and insights. René van der Kruk provided us with useful data he used for his wetland study. The Dutch national Railway Company (NS) was helpful at every stage by providing data and insightful ideas. Special thanks go to Mark van Hagen and his colleagues at NS. People at the GEODAN were also helpful by geo-coding the houses to make them ready for accessibility analysis and many others. 


\section{References:}

Alonso, William. 1964. "Location and Land Use: Toward a General Theory of Land Rent." Cambridge, MA: Harvard University Press.

Bajic, V. 1983. "The Effects of a New Subway Line on Housing Prices in Metropolitan Toronto." Urban Studies, 2: 147-58.

Bertolini, Luca and Tejo Spit. 1998. "Cities on Rails: The redevelopment of Railway Station Areas.” E \& FN Spon, London.

Bowes, David R., and Keith R. Ihlanfeldt. 2001. "Identifying the Impacts of Rail Transit Stations on Residential Property Values." Journal of Urban Economics, 50: 1-25.

Cervero, R., and B. Susantono. 1999. "Rent Capitalization and Transportation Infrastructure Development in Jakarta." Review of Urban and Regional Development Studies, 11 issue 1: $11-23$.

Cervero, Robert and Michael Duncan. 2001. "Rail Transit's Value Added: Effect of Proximity to Light and Commuter Rail Transit on Commercial Land Values in Santa Clara County California.” Paper prepared for National Association of Realtors Urban Land Institute.

Cervero, Robert. 1984. "Light Rail Transit and Urban Development." Journal of the American Planning Association, 50: 133-147.

Damm, D., S. R. Lerman, E. Lerner-Lam, and J. Young. 1980. "Response of urban real estate values in anticipation of the Washington Metro." Journal of Transport Economics and Policy, 14: 315-336.

Debrezion, Ghebreegziabiher, Eric Pels and Piet Rietveld 2006. "The Impact of Railway Stations on Residential and Commercial Property value: A Meta Analysis." Journal of Real Estate Finance and Economics, Forthcoming

Dewees, D. N., 1976. "The effect of a subway on residential property values in Toronto." Journal of Urban Economics, 3: 357-369. 
Dornbusch, D. M., 1975. "BART-induced changes in property values and rents, in Land Use and Urban Development Projects, Phase I, BART: Final Report.” Working Paper WP 21-5-76, U.S. Department of Transportation and U.S. Department of Housing and Urban Development.

Fejarang, Robert A. 1994. "Impact on Property Values: A Study of the Los Angeles Metro Rail." Preprint, Transportation Research Board, $73^{\text {rd }}$ Annual Meeting, Washington, D. C., January $9-13$.

Fujita, M. 1989. “Urban Economic Theory.” Cambridge University Press, Cambridge

Gatzlaff, D. and M. Smith. 1993. "The Impact of the Miami Metrorail on the Value of Residences Station Locations.” Land Economics, 69: 54-66.

Giuliano, D. 1986. "Land Use Impacts of Transportation Investments: Highway and Transit." Hanson, editor, Geography of Urban Transportation, New York: Guilford.

Goldberg, M.A. 1981. "Transportation Systems and Urban forms: Performance Measurement and Data Requirements." Proceedings of the International Symposium on Surface Transportation Performance, 256-68.

Gordon. P., and H. W. Richardson. 1989. "Gasoline Consumption and the Cities: A Reply." Journal of the American Planning association, 55: 342-45.

Grass, R. G. 1992. "The estimation of residential property values around transit station sites in Washington, D.C.” Journal of Economics and Finance, 16: 139-146.

Hansen, W.G. 1959. "How accessibility shapes Land Use." Journal of American Institute of Planners, 25: 73-76.

Landis, John, Robert Cervero, Subhrajit Guhathukurta, David Loutzenheiser, and Ming Zhang. 1995. "Rail Transit Investments, Real Estate Values, and Land Use Change: A Comparative Analysis of Five California Rail Transit Systems.” Monograph 48, Institute of Urban and Regional Studies, University of California at Berkeley. 
Lee, D. B. 1973. "Case Studies and Impacts of BART on Prices of Single Family Residences." University of California, Institute of Urban and Regional Development, Berkeley, CA.

Martellato, D., P. Nijkamp and A. Reggiani. 1998. "Measurement and measures of network accessibility: economic perspectives.” in: M. Beuthe \& P. Nijkamp (eds.), Advances in European transport policy analysis, Aldershot, Avebury.

Muth, R. F. 1969. "Cities and Housing.” University of Chicago Press, Chicago.

Nelson, Arthur C. 1998. "Transit Stations and Commercial Property Values: Case Study with Policy and Land Use Implications." Presented at Transportation Research Board 77th Annual Meeting.

NEORail II. 2001. "The Effect of rail Transit on Property Values: A Summary of Studies." (Draft).

RICS, Policy Unit. 2002. "Land Value and Public Transport: stage 1- Summary of findings."

Rosen, Sherwin. 1974. "Hedonic Pricing and Implicit Markets: Product differentiation in Pure competition." Journal of Political Economy, 82, issue 1: 34-55.

Smith, V. Kerry and Ju-Chin Huang. 1995. "Can markets Value Air Quality? A Meta-analysis of Hedonic Property value Models.” Journal of Political Economy, 103, issue 1: 209-227.

Vessali, Kaveh V. 1996. "Land Use Impacts of rapid Transit: A Review of Empirical Literature.”, Berkeley Planning Journal, 11: 71-105.

Voith, R. 1991. "Transportation, Sorting and House Values." Journal of the American Real Estate Urban Economics Association, 19: 117-37.

Voith, Richard. 1993. "Changing Capitalization of CBD-Oriented Transportation Systems: Evidence from Philadelphia." 1970 - 1988. Journal of Urban Economics, 33: 361-376.

Von Thünen, Johan. 1830. "Der Isolierte staat in Beziehung auf Landwirschaft und nationalokonomie.” Munich: Pflaum. 
Weinstein, Bernard L. and Terry L. Clower 1999. "The Initial Economic Impact of the DART LRT system.” Unpublished manuscript. 